\title{
Applying the Popular Opinion Leader Intervention for HIV to COVID-19
}

\author{
Katherine G. Quinn ${ }^{1}$
}

Published online: 25 June 2020

(c) Springer Science+Business Media, LLC, part of Springer Nature 2020

The 2019 novel coronavirus disease (COVID-19) pandemic has demanded an immediate public health response and community-wide adoption of various behavior change strategies. Public health guidelines and recommendations emerged rapidly and have been modified as the pandemic has shifted. As a result, the public has received inconsistent and occasionally inaccurate information, contributing to misinformation and mistrust of public health recommendations [1]. As Jaiswal et al. have recently noted, the spread of medical mistrust and public health misinformation evident in the current COVID-19 pandemic mirrors long-standing challenges in the HIV epidemic [1]. Accordingly, we can take lessons learned from the HIV epidemic about the spread of public health information and its effects on behavior change apply them to the current pandemic. This Note focuses on social networks and the popular opinion leader model, which may be key in disseminating trusted information about COVID-19 in a rapidly changing public health landscape.

Social networks are critical in norm formation and behavioral adoption, and have been shown to impact a variety of public health outcomes, including HIV [2-5]. Since the early years of the HIV epidemic, social network interventions have been used to disseminate trusted information to vulnerable communities $[6,7]$. Based on diffusion of innovation theory [8], the Popular Opinion Leader (POL) model posits that behavior change is achieved when new risk-reducing methods for HIV are disseminated by social network opinion leaders through their personal networks. As outlined by Kelly, the POL model identifies socially influential members of a population who have sufficient large social networks. These individuals are then trained in how to effectively communicate risk reduction strategies to their peers during everyday conversations and are able to establish momentum as a community social movement $[9$,

Katherine G. Quinn

kaquinn@mcw.edu

1 Center for AIDS Intervention Research (CAIR), Medical College of Wisconsin, Milwaukee, WI, USA
10]. Designed as a community-level intervention targeting gay and bisexual men, this intervention has demonstrated effectiveness at increasing HIV prevention knowledge and behaviors, facilitating PEP interest and uptake, and reducing HIV-related stigma [10-14].

Social network and POL interventions may be particularly applicable to other public health crises, including COVID19. Similar to HIV, the early COVID-19 pandemic has been characterized by stigma, misinformation, and medical mistrust $[1,15]$. Perceptions of blame, personal responsibility, and infection risk contribute to detrimental health outcomes and quality of life among affected individuals and those perceived to be at-risk. Furthermore, stereotypes and judgments about disproportionately affected groups can generate stigma and inform the public response to disease [16]. For example, asymptomatic individuals who are infected with coronavirus have been referred to as "carriers" [17] reminiscent of the narrative surrounding "HIV carriers" evident in the early years of the disease. This type of terminology can contribute to fear, public perceptions about who might be a "carrier," and stigma about certain groups of people.

The COVID-19 outbreak began in Wuhan, China, which sparked early reports of racism and xenophobia toward Asian Americans in the United States (US). Since midMarch 2020, there have been over 1,700 reports of racism and xenophobia toward Asian Americans, including microaggressions and violent attacks [18]. In the months following, the concentration of diagnoses and deaths related to COVID-19 in African American and Latinx communities illuminated long-standing structural racism in the US [19, 20], and led to blame of Black individuals for high mortality rates within their communities [20]. Emerging data show stark racial disparities in COVID-19. For example, one analysis found that counties that had majority-Black -populations had COVID-19 infection rates three times that of majority-white counties [21]. Additionally, a Centers for Disease Control and Prevention analysis found that of nearly 1500 hospitalizations due to COVID-19, nearly one-third were among Black people, despite accounting for $18 \%$ of the population in the areas studied [22]. 
Similar to the disparities evident in HIV/AIDS, the stark racial disparities in COVID-19 are rooted in systemic and contemporary racism and health and economic inequity that has made Black Americans more vulnerable to the virus. Stigma resulting from xenophobia or racism can limit access to accurate public health information, alienate communities from needed prevention and treatment resources, and further contribute to disparities in disease outcomes [23-25]. Similarly, misinformation about COVID-19 has emerged as a result of medical mistrust, which has also plagued the public health response to the HIV epidemic [13, 26, 27]. Medical mistrust is a primary driver of racial and ethnic health inequities [28] and can stem from historical and persistent racism, oppression, and disadvantage faced by people of color in the United States. Similar to what has been documented in the HIV literature [25-27, 29], medical mistrust may contribute to lack of COVID-19 testing, delayed access to needed medical care, and misinformation about COVID-19.

Yet, engaging trusted community leaders and social influencers to disseminate accurate public health information may help overcome these challenges to address inequities reduce COVID-19 stigma, and strengthen norms that contribute to sustained behavior change (e.g. social distancing, mask wearing, hand washing). Trusted influencers from within one's community who endorse COVID-19 prevention steps can add trust and credibility to public health messaging, particularly if there is mistrust of official authorities (e.g. medical system, public health departments, and state and local government). Our prior research has shown that peer endorsements and health advice from friends and members of one's social network are effective at facilitating population-level HIV behavior change [13, 30]. As we have demonstrated $[13,30]$, most community members want to help friends in a time of crises. Endorsements by popular opinion leaders within their social networks convey that health protective steps are possible, can reduce stigma, strengthen peer norms concerning the benefits of taking protective measures, and increase solidarity $[5,13,30]$. In racial and ethnic minority communities where medical mistrust is high [31, 32], advice from personally known and trusted individuals establishes information credibility and can help overcome mistrust and misinformation [33].

\section{Applying the POL Model to COVID-19}

Given our experience implementing the POL model with populations at risk for HIV, we are currently applying this model to communities being affected by COVID-19. As has been documented in many parts of the country, there are significant racial and ethnic disparities in COVID-19 in Milwaukee [34, 35]. Although 6.7\% of Wisconsin's residents are Black, they have comprised $21 \%$ of confirmed
COVID-cases and $29 \%$ of COVID-related deaths. Additionally, over $30 \%$ of COVID cases are among individuals who identify as Hispanic or Latino, although they represent just $6.9 \%$ of the state's population [35].

With funding from the Advancing a Healthier Wisconsin Endowment, our project, 1000 Hometown Heroes, aims to engage 1000 local "heroes" in Milwaukee from predominantly African American and Latinx communities in an effort to address the racial and ethnic disparities in COVID-19. These 'heroes' are social influencers and leaders on various social media platforms who will share accurate, culturally relevant, tailored information about COVID-19 with their networks. We are recruiting POL who see themselves as change agents, want to help protect the health and psychosocial well-being of others in their communities, and are willing to spread the word about COVID-19 prevention and reduce disease stigma. Additionally, we are providing influencers information to connect community members to needed services, provide strategies to cope with stress, anxiety, and social distancing, and provide accurate, up-to-date information about the status of COVID-19 in the Milwaukee area. Aligned with social distancing guidelines for COVID-19 prevention, we are using online social networks as an efficient and effective way to disseminate accurate information and influence community norms and behaviors [36]. The POL model has been successfully adapted to online networks, allowing peer influencers to reach a large number of people in a cost-effective approach [37].

In many ways, this approach is a modernization of efforts implemented during the 1918 flu pandemic. Postal workers, Boy Scouts, and teachers, as trusted community members, were asked to volunteer for health education campaigns and go door-to-door to educate families about public health practices [38]. With the advent of numerous social media platforms, we now have an opportunity for more efficient information spread from a larger segment of the population. Over the next six months, we will be evaluating the program's reach and effectiveness, which may provide some early indication about how to quickly disseminate accurate, trusted information during public health crises, particularly to communities hardest hit by an epidemic.

Adapting the popular opinion model, which has demonstrated significant success in HIV prevention, to COVID19 is one example of how HIV prevention and intervention researchers can take lessons learned in HIV and apply them to current and future pandemics. While much of our current HIV research is on hold indefinitely, we have an opportunity to pivot and use what we have learned from nearly four decades of HIV research to assist in addressing the impact of COVID-19. We have a wealth of knowledge about infectious disease, stigma, sustained behavior modification, and social and structural facilitators of health disparities that should 
be adapted and shared to address other emerging infectious diseases.

Acknowledgements Special thanks to Jeffrey A. Kelly, $\mathrm{PhD}$ for his direction and guidance on this work. Funding for 1000 Hometown Heroes comes from the Advancing A Healthier Wisconsin Endowment, which allowed for a swift response from the research community in Milwaukee to address the COVID-19 pandemic.

\section{References}

1. Jaiswal J, LoSchiavo C, Perlman D. Disinformation, misinformation and inequality-driven mistrust in the time of COVID-19: lessons unlearned from aids denialism. AIDS Behav. 2020. https ://doi.org/10.1007/s10461-020-02925-y.

2. Schneider JA, Cornwell B, Ostrow D, Michaels S, Schumm P, Laumann EO, et al. Network mixing and network influences most linked to HIV infection and risk behavior in the HIV epidemic among black men who have sex with men. Am J Public Health. 2013;103:e28-36.

3. Rosenquist JN, Murabito J, Fowler JH, Christakis NA. The spread of alcohol consumption behavior in a large social network. Ann Intern Med. 2010;152:426-33.

4. Latkin CA, Kuramoto SJ, Davey-Rothwell MA, Tobin KE. Social norms, social networks, and HIV risk behavior among injection drug users. AIDS Behav. 2010;14:1159-68.

5. Amirkhanian YA, Kelly JA, Takacs J, McAuliffe TL, Kuznetsova AV, Toth TP, et al. Effects of a social network HIV/STD prevention intervention for MSM in Russia and Hungary: a randomized controlled trial. AIDS. 2015;29:583-93.

6. Kelly JA, Murphy DA, Sikkema KJ, McAuliffe TL, Roffman RA, Solomon LJ, et al. Randomised, controlled, community-level HIVprevention intervention for sexual-risk behaviour among homosexual men in US cities. Lancet. 1997;350:1500-5.

7. Amirkhanian YA. Social networks, sexual networks and HIV risk in men who have sex with men. Curr HIV/AIDS Rep. 2014;11:81-92.

8. Rogers EM. Diffusion of Innovations-Fourth Edition. Rogers: Everett M; 1995.

9. Kelly JA. Popular opinion leaders and HIV prevention peer education: resolving discrepant findings, and implications for the development of effective community programmes. AIDS Care. 2004; $16: 139-50$

10. Kelly JA, St. Lawrence JS, Diaz YE, Stevenson LY, Hauth AC, Brasfield TL, et al. HIV risk behavior reduction following intervention with key opinion leaders of population: an experimental analysis. Am J Public Health. 1991;81:168-71.

11. Theall KP, Fleckman J, Jacobs M. Impact of a community popular opinion leader intervention among African American adults in a southeastern united states community. AIDS Educ Prev. 2015;27:275-88.

12. Li L, Guan J, Liang LJ, Lin C, Wu Z. Popular opinion leader intervention for HIV stigma reduction in health care settings. AIDS Educ Prev. 2013;25:327-35.

13. Quinn KG, Christenson E, Spector A, Amirkhanian Y, Kelly JA. The influence of peers on PrEP perceptions and use among young black gay, bisexual, and other men who have sex with men: a qualitative examination. Arch Sex Behav. 2020. https://doi. org/10.1007/s10508-019-01593-x.

14. Hosek SG, Lemos D, Hotton AL, Isabel Fernandez M, Telander $\mathrm{K}$, Footer D, et al. An HIV intervention tailored for black young men who have sex with men in the House Ball Community. AIDS Care. 2015;27:355-62.
15. Nature. Stop the coronavirus stigma now. Nature. 2020;580:165.

16. Mak WWS, Mo PKH, Cheung RYM, Woo J, Cheung FM, Lee D. Comparative stigma of HIV/AIDS, SARS, and Tuberculosis in Hong Kong. Soc Sci Med. 2006;63:1912-22.

17. Cleveland Clinic. No signs of coronavirus? Here's why you could be carrying (and spreading) it [Internet]. https://healt h.clevelandclinic.org/studies-show-carriers-with-mild-or-nosymptoms-are-key-part-of-covid-19-spread/

18. Choi C, Kulkarni M. In Six Weeks , STOP AAPI HATE Receives Over 1700 Incident Reports of Verbal Harassment, Shunning and Physical Assaults [Internet]. Los Angeles, CA; 2020. https://www.asianpacificpolicyandplanningcouncil.org/ wp-content/uploads/Press_Release_5_13_20.pdf

19. Bailey ZD, Krieger N, Agénor M, Graves J, Linos N, Bassett MT. Structural racism and health inequities in the USA: evidence and interventions. Lancet. 2017;398:1453-63.

20. Kendi I. Stop blaming Black people for dying fo the coronavirus. Atl [Internet]. https://www.theatlantic.com/ideas/archi ve/2020/04/race-and-blame/609946/

21. Thebault $\mathrm{R}, \mathrm{Ba}$ Tran A, Williams $\mathrm{V}$. The conronavirus is infecting and killing black Americans at an alarmingly high rate. Washington Post [Internet]. 2020 Apr 7; https://www.washi ngtonpost.com/nation/2020/04/07/coronavirus-is-infectingkilling-black-americans-an-alarmingly-high-rate-post-analy sis-shows/?arc404=true

22. Garg S, Kim L, Whitaker M, O'Halloran A, Holstein R, et al. Hospitalization rates and characteristics of patients hospitalized with laboratory-confirmed coronavirus disease 2019-COVIDNET, 14 States, March 1-30, 2020. MMWR Morb Mortal Wkly Rep. 2020;69:458-64.

23. Quinn K. Applying an intersectional framework to understand syndemic conditions among young Black gay, bisexual, and other men who have sex with men. Soc Sci Med. 2019. https://doi. org/10.1016/j.socscimed.2019.112779.

24. Arscott J, Humphreys J, Merwin E, Relf M. "That Guy is Gay and Black. That's a Red Flag." How HIV stigma and racism affect perception of risk among young Black men who have sex with men. AIDS Behav. 2020;24:173-84.

25. Quinn KG, Dickson-Gomez J, Zarwell M, Pearson B, Lewis M. "A gay man and a doctor are just like, a recipe for destruction": how racism and homonegativity in healthcare settings influence PrEP uptake among young Black MSM. AIDS Behav. 2019;23:1951-63.

26. Kalichman SC, Eaton L, Kalichman MO, Grebler T, Merely C, Welles B. Race-based medical mistrust, medication beliefs and HIV treatment adherence: test of a mediation model in people living with HIV/AIDS. J Behav Med. 2016;39:1056-64.

27. Quinn KG, Kelly JA, DiFranceisco WJ, Tarima SS, Petroll AE, Sanders C, et al. The health and sociocultural correlates of AIDS genocidal beliefs and medical mistrust among African American MSM. AIDS Behav. 2016;22:1814-25.

28. Smedley BD, Stith AY, Nelson AR. Unequal Treatment: Institute of Medicine (US) Committee on Understanding and Eliminating Racial and Ethnic Disparities in Healthcare. Unequal treat. Washington: National Academic Press; 2003.

29. Bogart LM, Wagner G, Galvan FH. Conspiracy beliefs about HIV are related to antiretroviral treatment nonadherence among African American men with HIV. J Acquir Immune Defic Syndr. 2010;53:648-55.

30. Kelly JA, Amirkhanian YA, Walsh JL, Brown KD, Quinn KG, Petroll AE, et al. Social network intervention to increase preexposure prophylaxis (PrEP) awareness, interest, and use among African American men who have sex with men. AIDS Care. 2020;32:40-6.

31. Malebranche DJ, Peterson JL, Fullilove RE, Stackhouse RW. Race and sexual identity: perceptions about medical culture and 
healthcare among Black men who have sex with men. J Natl Med Assoc. 2004;96:97-107.

32. Eaton LA, Driffin DD, Kegler C, Smith H, Conway-Washington $\mathrm{C}$, White $\mathrm{D}$, et al. The role of stigma and medical mistrust in the routine health care engagement of black men who have sex with men. Am J Public Health. 2015;105:e75-82.

33. Phillips G II, Raman A, Felt D, McCuskey D, Hayford C, Picket J, et al. PrEP4Love: the role of messaging and prevention advocacy in PrEP attitudes, perceptions, and uptake among YMSM and transgender women. JAIDS J Acquir Immune Defic Syndr. 2020;83:450-6.

34. Rast J. Milwaukee's Coronavirus Racial Divide: A report on the early stages of COVID-19 spread in Milwaukee County [Internet]. Milwaukee, WI; 2020. https://uwm.edu/ced/wp-content/uploads/ sites/431/2020/04/COVID-report-final-version.pdf

35. Jannene J. COVID-19 testing up but racial disparities still stark [Internet]. Urban Milwaukee. https://urbanmilwaukee. com/2020/05/09/daily-as-covid-19-testing-increases-racial-dispa rity-remains-stark/
36. Limaye RJ, Sauer M, Ali J, Bernstein J, Wahl B, Barnhill A, et al. Building trust while influencing online COVID-19 conent in the social media world. Lancet. 2020;2:E277-E278278.

37. Ko NY, Hsieh CH, Wang MC, Lee C, Chen CL, Chung AC, et al. Effects of internet popular opinion leaders (ipol) among internet-using men who have sex with men. J Med Internet Res. 2013;15:e40.

38. Ott M, Shaw SF, Danila RN, Lynfield R. Lessons learned from the 1918-1919 influenza pandemic in Minneapolis and St. Paul, Minnesota. Public Health Rep. 2007;122:803-10.

Publisher's Note Springer Nature remains neutral with regard to jurisdictional claims in published maps and institutional affiliations. 